\title{
AVALIAÇÃO MEDIADORA NO CONTEXTO DA EDUCAÇÃO INFANTIL
}

\author{
Charlene Ferreira SILVA* \\ Douglas Carvalho De MENEZES**
}

Resumo: O presente trabalho foi desenvolvido com o intuito de refletir sobre a avaliação na Educação Infantil e como a postura mediadora e investigativa do professor faz toda a diferença no desenvolvimento do aluno. Nas instituições escolares predomina uma avaliação que não traduz a evolução das crianças na Educação Infantil. Muitos professores ainda utilizam de relatórios/diagnósticos da vida escolar do aluno permeados de comparações e de julgamentos como quesitos para avaliar o desenvolvimento das crianças. A criança não é tomada como ponto de partida nos seus planejamentos, não há redefinição de postura diante dos erros e acertos, não há uma intervenção pedagógica que desafie a criança a evoluir, crescer. Dessa maneira, esse trabalho pretende descrever e analisar a prática da avaliação mediadora, que, parte do princípio de que cada momento da vida da criança representa uma etapa altamente significativa e que precedente às suas próximas conquistas, descobertas, curiosidades, sendo respeitadas em sua singularidade.

*Especialista em Coordenação Pedagógica pela Universidade Federal de Uberlândia charlenesferreira@yahoo.com

*** Mestre em educação pela Universidade Federal de Uberlândia. douglasmatufu@yahoo.com.br

(C) Silva; Menezes - DiversaPrática, v. 4, n. 1, p. 43-70 - $1^{\circ}$ semestre 2017 
Palavra Chave: Avaliação; Avaliação na Educação Infantil; Avaliação Mediadora.

Abstract: The present work was developed with the purpose of reflecting on the evaluation in Early Childhood Education and how the mediator and investigative posture of the teacher makes all the difference in the development of the student. In school institutions, an evaluation that does not reflect the evolution of children in Early Childhood Education predominates. Many teachers still use reports / diagnoses of the student's school life permeated by comparisons and judgments as questions to assess the development of children. The child is not taken as a starting point in his planning, there is no redefinition of posture in the face of mistakes and correctness, there is no pedagogical intervention that challenges the child to evolve, to grow. In this way, this work intends to describe and analyze the practice of mediating evaluation, which, based on the principle that each moment of the child's life represents a highly significant stage and that precedes their next conquests, discoveries, curiosities, being respected in their singularity.

Keyword: Evaluation; Evaluation in Early Childhood Education; Mediator Evaluation. 


\section{INTRODUÇÃO}

A Educação Infantil até chegar às concepções de hoje, passou por um longo desenrolar histórico. Proveniente da necessidade dos adultos após a inserção da mulher no mercado de trabalho, a creche surgiu, fundamentalmente, como espaço para acolher os filhos enquanto os seus pais trabalhavam, principalmente as mães.

Esse cenário da Educação Infantil muda quando há a aprovação da Lei de Diretrizes e Bases da Educação Nacional - LDB - 9394/96, a qual incorpora as creches e pré-escolas como instituições de educação infantil. Conforme a LDB, a Educação Infantil tem como finalidade o desenvolvimento integral da criança até seis anos de idade, em seus aspectos físico, psicológico, intelectual e social, complementando a ação da família e da sociedade.

Essa legislação apresenta a avaliação como ponto chave para o desenvolvimento da aprendizagem do educando, observada no Art.31 que regulamenta que a avaliação far-se-á mediante acompanhamento e registro do seu desenvolvimento, sem o objetivo de promoção (BRASIL, 1996). Aqui, percebe-se a importância do professor como o autor de propostas pedagógicas que possam garantir a aprendizagem e o desenvolvimento infantil respeitando as particularidades dessa faixa 
etária, efetivando a escola de educação infantil como um espaço de educação de qualidade, permitindo vivências e experiências educativas, comprometida com os direitos fundamentais da criança e garantindo a promoção da cidadania.

O presente trabalho científico é desenvolvido com o intuito de refletir sobre a avaliação na Educação Infantil e como a postura mediadora e investigativa do professor faz toda a diferença no desempenho do aluno. A pesquisa tem como objetivo a busca da resposta da seguinte indagação: Como provocar o professor a um olhar sensível e reflexivo no ato avaliativo para a garantia da aprendizagem e desenvolvimento da criança de 2 à 5 anos?

A pesquisa se justifica pelo fato de se predominar nas instituições escolares uma avaliação que não traduz a verdadeira evolução das crianças na educação infantil. Professores ainda utilizam de relatórios/diagnósticos da vida escolar do aluno, recheados de comparações e de julgamentos como quesitos para avaliar o desenvolvimento das crianças. A criança não é tomada como ponto de partida dos seus planejamentos, não há redefinição de postura diante dos erros e acertos, não há uma intervenção pedagógica que desafie a criança a evoluir, crescer. Sem essa ação pedagógica, não há como 
completar o ciclo da avaliação na sua concepção de continuidade, de ação-reflexão-ação.

Para que se repense a forma de avaliar das instituições e para provocar os professores, o trabalho pretende descrever e analisar a prática da avaliação mediadora, que parte do princípio de que cada momento da vida da criança representa uma etapa altamente significativa e precedente às suas próximas conquistas, que a Educação Infantil é essencial para a sua vida futura, mas que, para tanto, o ambiente pedagógico precisa respeitá-la e valorizá-la em seu próprio tempo.

Se respeitadas e desafiadas, adequadamente, a realizar novas descobertas, a pensar sobre as coisas e a expressar suas ideias, irão naturalmente se desenvolver, mas para isso, o professor deve assumir uma postura mediadora. Quando isso acontece, ele toma consciência do seu papel de protagonista do processo educativo, participando efetivamente da evolução do seu aluno.

Para responder o problema da pesquisa e alcançar os objetivos pretendidos é desenvolvido um estudo de natureza bibliográfica. A pesquisa bibliográfica é o passo inicial na construção efetiva de um protocolo de investigação, quer dizer, após a escolha do assunto é necessário fazer uma revisão bibliográfica do tema apontado. Um 
trabalho que trata da pesquisa bibliográfica não pode deixar de conter explanações e estas devem seguir um fluxo que facilite a compreensão e a aplicação. A presente pesquisa bibliográfica se baseia nos estudos de Hoffmann (2012), Brasil (1996), Brasil (1998), Brasil (2006).

Abordar o tema "Avaliação na Educação Infantil” é complexo porque não podemos desarticulá-lo da concepção de criança na atualidade, as teorias de construção do conhecimento, as questões curriculares e a constituição do cenário educativo para crianças de 2 à 5 anos, tornando o tema mais teórico do que prático.

\section{DESENVOLVIMENTO}

\subsection{Avaliação mediadora: pressupostos e ações.}

Para começar a falar sobre avaliação, primeiramente é preciso alertar que as diretrizes legais estabelecidas sobre a avaliação na Educação Infantil, nas últimas décadas, recomendam que esta não deva incorrer a caráter de aprovação e reprovação. Na Política Nacional de Educação Infantil: pelo direito da criança de 0 a 6 anos à educação, a avaliação é citada como parte das propostas pedagógicas, onde são explicitadas as concepções, as diretrizes referentes a metodologia de trabalho pedagógico, “(...) prevendo a avaliação como parte do trabalho 
pedagógico, que envolve toda a comunidade escolar" (BRASIL, 2006, p.18). O que significa avaliar?

De acordo com o dicionário informal, avaliar significa "processo que visa verificar a aquisição de competências e habilidades em determinada área do conhecimento ou do campo laboral". No caso da educação infantil, se não é para promover para as séries posteriores qual seria o objetivo de avaliar as crianças de 2 à 5 anos? Avaliar na educação infantil então não é julgar o que a criança sabe ou não, mas sim, acompanhar o percurso de vida durante a qual ocorrem mudanças em múltiplas dimensões com a intenção de favorecer o máximo possível seu desenvolvimento.

Ao dizer, "acompanhar o percurso de vida da criança" já deixa claro que a criança não percorrerá sozinha, o professor vem como o acompanhante, observando-as, seguindo os seus movimentos, intervindo, mediando. Avaliar é acompanhar. Ainda pode se destacar o trecho "favorecer ao máximo seu desenvolvimento", onde através da observação o professor auxiliará, através de um fazer pedagógico que contribua efetivamente para o seu desenvolvimento.

Sendo assim, Hoffman (2012) afirma que avaliar, na concepção mediadora, que é a concepção tratada nesse artigo, engloba necessariamente a intervenção pedagógica. Não basta o professor estar 
ao lado da criança, observando-a, analisando-a, ele deve planejar atividades e ações pedagógicas, reorganizar $o$ ambiente de aprendizagem/alfabetizador, rever e redefinir sua postura e muitas outras ações, com base no que se observa no cotidiano de sua sala de aula. Ainda para Hoffmann (2012), esses procedimentos são inerentes ao processo avaliativo. Sem a avaliação pedagógica não se contempla o ciclo de avaliação na concepção de continuidade, de ação-reflexãoação.

O cenário de uma sala de aula com crianças de 2 à 5 anos traduz a dinamicidade e flexibilidade da Educação Infantil. A professora organiza uma atividade para três a quatro alunos com tintas e pincéis para que expressem livremente sua criatividade, no outro canto da sala as professoras auxiliares participam de uma atividade de montagem de peças de lego com as outras crianças. Nesse mesmo momento, uma criança pede para ir ao banheiro e a funcionária da escola informa que está na hora de organizarem os alunos para o momento cultural. Todas essas pessoas envolvidas no contexto dessa sala cuidam, observam, orientam, conversam, chamam a atenção, sem tirar os olhos das 20 crianças do grupo. Na cena descrita, caracterizam-se dois princípios que norteiam a avaliação na concepção mediadora: principio da individualização e o principio da mediação. 
O princípio da individualização está relacionado ao observar e cuidar mais e por mais tempo da criança que estiver precisando de maior assistência naquele determinado momento. Assim, preserva-se a liberdade e espontaneidade de cada uma, dando espaço para a reflexão as ações educativas pertinentes ao interesse de todas.

O princípio da mediação vem como norte da intenção de desenvolver estratégias pedagógicas desafiadoras de modo que todas as crianças encontrem a possibilidade de evoluírem em todas as áreas do conhecimento, seguras e com iniciativa para inventar, descobrir e experimentar.

No volume 3 do Referencial Curricular para a Educação Infantil (BRASIL, 1998) é abordado essas áreas do conhecimento como “Conhecimento de Mundo”, subdividindo as em Movimento, Música, Artes visuais, Linguagem oral e escrita, Natureza e sociedade e Matemática. Para cada área do conhecimento são apresentadas "Orientações gerais para o professor" que incluem "Observação, registro e avaliação". Esses tópicos tratados no referencial vêm em conformidade com a legislação vigente, e trazem a visão da avaliação como um conjunto de ações que ajudam o professor a refletir sobre as condições de aprendizagem oferecidas em sua sala de aula/escola e ter 
condições de ajustar sua prática às necessidades das crianças. $\mathrm{O}$ documento ainda completa que

É um elemento indissociável do processo educativo que possibilita ao professor definir critérios para planejar as atividades e criar situações que gerem avanços na aprendizagem das crianças. Tem como função acompanhar, orientar, regular e redirecionar esse processo como um todo (BRASIL, 1998, v. 1, p.59).

Essa dinamicidade e flexibilidade que envolve a rotina da educação infantil caracterizam o olhar avaliativo: viver a espontaneidade de cada momento, estabelecendo o múltiplo diálogo com as crianças, com a sensibilidade e o conhecimento necessário para fazer provocações diferentes a cada minuto e direcionadas a cada uma, diversificando o apoio pedagógico sem discriminar, rotular, desrespeitar o tempo e o jeito da criança, ou seja, uma avaliação mediadora.

A avaliação mediadora parte do pressuposto, o que faz toda a diferença em avaliar é a postura mediadora do professor. Sem a promoção de desafios a partir daquilo que observou, refletiu, é pouco provável que a criança venha a construir os conhecimentos necessários ao seu desenvolvimento, sem que ocorra uma ação pedagógica mediadora e desafiadora. 
Como embasamento teórico, toma-se por base as teorias construtivistas e sociointeracionistas que alertam sobre a importância de interferências mediadoras para que a criança tenha melhores oportunidades de desenvolvimento intelectual e moral.

De acordo com Piaget, a criança aprende construindo e reconstruindo o seu pensamento, através da assimilação e acomodação das suas estruturas. Sua teoria tem como objetivo central a necessidade de estudar a gênese dos processos mentais, ou seja, como esses processos são construídos ao longo da vida do indivíduo. O conhecimento resultaria de interações que produzem entre o sujeito e o objeto. A troca inicial entre sujeito e objeto se daria a partir da ação do sujeito.

A teoria de Piaget destaca a proposta de entender como que as crianças constroem os seus conhecimentos/ suas aprendizagens para que as práticas pedagógicas possam ser adequadas aos níveis de desenvolvimento das mesmas. Dessa forma ele estruturou um modelo de desenvolvimento que se caracteriza por processos de equilibrações sucessivas, onde o desenvolvimento psíquico inicia no nascimento e vai evoluindo até a maturidade, sendo comparada com o crescimento orgânico, que se fundamenta em encontrar o equilíbrio. 
Todo esse conhecimento é uma construção que vai sendo elaborado desde a infância, por meio de interações do sujeito com os objetos que procura conhecer, sejam eles do mundo físico ou do mundo cultural. O conhecimento resulta de uma inter-relação do sujeito que conhece com objeto a ser conhecido. Assim, cabe aos adultos mediar a aquisição de ferramentas culturais das crianças de forma a levá-las a refletir sobre as suas experiências, articulando ideias e construindo compreensões cada vez mais rica acerca da realidade. O professor mediador oportuniza e favorece processos de reflexão da criança sobre suas próprias ações.

Vygotsky fez uma grande contribuição em termos de avaliação de aprendizagem com sua teoria sociointeracionista onde a ação da criança é o ponto essencial para o seu desenvolvimento. A criança aprende pela interação com os elementos de sua cultura e do seu meio social e não apenas pelos estímulos do meio ambiente. Todas as crianças têm possibilidades de se desenvolver e, assim, deve se procurar analisar o seu potencial e não determinar suas capacidades em algum momento para simplesmente apontá-las/julgá-las como se observa nas práticas tradicionais da avaliação. Um professor desafiador/mediador tem papel crucial de levar a criança a avançar nas suas concepções de 
mundo tomando como ponto o conhecimento que já está consolidado, provocando avanços que não aconteceriam de forma espontânea.

Pode se perceber, que, em termos de mediação, tanto Piaget quanto Vygotsky fundamentam o papel do professor em termos de processos favorecedores à construção do conhecimento e defendem a importância da interação adulto/criança e criança/criança para o seu pleno desenvolvimento no plano moral e intelectual, assim como também sugerem a ação pedagógica como prática do professor mediador.

A prática avaliativa mediadora, em Educação Infantil tem por base os pressupostos teóricos até então enunciados. Partindo do princípio de que cada momento da vida da criança representa uma etapa altamente significativa e precedente às suas próximas conquistas, que a Educação Infantil é essencial para a sua vida futura, mas que, para tanto, o ambiente pedagógico precisa respeitá-la e valorizá-la em seu próprio tempo. Avaliar é construir estratégias de acompanhamento da história que cada criança vai construindo ao longo de sua vivencia na escola e fora dela.

Dessa maneira, compreende-se também que não se pode propor às crianças desafios que estejam além de suas possibilidades em certo momento, correndo-se o risco de causar-lhes inseguranças e pressões 
desnecessárias. Se respeitadas e desafiadas, adequadamente, a realizar novas descobertas, a pensar sobre as coisas e a expressar suas ideias, irão, naturalmente, se desenvolver até onde for possível em termos de sua etapa de crescimento. Mas como deve-se avaliar o processo de construção do conhecimento na educação infantil na concepção da avaliação mediadora?

O primeiro passo é o professor entender que o processo avaliativo deve ser reflexivo por natureza, sendo à base de uma prática pedagógica consciente, dando abertura para que o mesmo possa entender as crianças com quem convive. Analisando quais pressupostos teóricos nutrem as suas curiosidades e, através de uma postura mediadora, provocativa e desafiadora desencadear a construção do conhecimento significativa, no caso, para ambos.

Quando o professor passa a "ver a criança como ela é" ele busca entender o embasamento de suas ações e pensamentos. Para isso, tal como Piaget propunha que o professor não deve seguir um roteiro com perguntas prontas, recheadas de intencionalidades e julgamentos, mas sim, observar, pontuar e registrar, gradativamente, os desafios, as hipóteses e os resultados da lógica do pensamento da criança, traçando a linha da construção do seu pensamento, da sua evolução. Mesmo que o professor tende encaixar as crianças em um padrão, se depararão com 
situações surpreendentes e inesperadas reações para cada criança numa mesma sala de aula, demonstrando sua singularidade.

As ações educativas dentro das instituições de Educação Infantil devem partir da observação e do diálogo entre os profissionais que diretamente e indiretamente participam do cotidiano das crianças. Nas primeiras semanas do ano letivo, os profissionais devem analisar as manifestações das crianças, suas atitudes, seus interesses, para conhecêlas nas suas individualidades e a partir daí articular o planejamento inicial de seu fazer pedagógico.

É procurando compreender as atividades espontâneas das crianças que vou, pouco a pouco, captando os seus interesses, os mais diversos. (...) por isso é que, em última análise, as propostas de trabalho nascem delas e de mim como professora. Não é de estranhar, pois, que as crianças se encontrem nas suas atividades e as percebam como algo delas, ao mesmo tempo em que vão entendendo o meu papel de organizador, e não de "dona de suas atividades" (FREIRE, 1989, p.21).

Muitos profissionais confundem o ato de "observar para desafiar" defendido pela concepção mediadora, com "observar para julgar”. Não é raro, professores observarem as crianças para constatar se elas gostaram ou não da atividade, se alcançaram ou não os resultados a fim de analisar se a prática pedagógica teve seus objetivos alcançados ou não. Essa observação é meramente para julgamento e não 
observação como ponto de partida para os próximos desafios, para dar continuidade ao planejamento.

Numa sala de ensino infantil, as crianças devem interagir com um ambiente livre de limitações e proibições; os professores devem estar interessados e brincar junto com elas para oportunizar vivências enriquecedoras e desafiadoras.

A criança não pode se sentir integrada a uma escola que lhe proporciona uma situação constante de prova, de teste, onde a tensão se mantém e onde a criança e sua família são prejulgadas e responsabilizadas pelo fracasso (...). São crianças que não passam numa prova de ritmo e sabem fazer uma batucada. Que não têm equilíbrio e coordenação motora e andam em muros e árvores. Que não tem discriminação auditiva e reconhecem cantos de pássaros (MACEDO, 1988, p. 48-51).

Conforme Macedo aponta, muitas instituições de Educação Infantil contrariam a finalidade de suas práticas avaliativas, reforçando tensões, resultando em "negações" como:

- Avaliação, na maioria das vezes, não é exercida em benefício das crianças: os processos avaliativos ocorrem, apenas, no sentido de observar as crianças durante um período de tempo, registrar em alguns momentos o que se observa e preencher instrumentais de avaliação correspondente ao desempenho observado. Esses instrumentais não têm como finalidade 
subsidiar a prática educativa dos professores, mas sim informar/registrar o trabalho desenvolvido na escola para os pais, diretores e secretaria da educação.

- Não há uma análise sobre as possibilidades das crianças realizarem as propostas pedagógicas as quais estão sendo avaliada: em muitos relatórios de avaliação vê - se registrado que a criança não realizou a atividade, a criança não se interessou, não tem atenção, não conseguem concentrar, entre outros. Essa criança pode estar sendo julgada por não participar de uma atividade que não condiz com seus interesses, ou a sua idade, até mesmo, por má condução do professor durante a atividade. Muitas ações de natureza curricular ou didática podem estar relacionadas à falta de embasamento teórico ao planejá-la e da falta de atenção às próprias crianças quanto às suas curiosidades e interesses.

- Os relatórios finais nem sempre contemplam a totalidade do desenvolvimento infantil: nota-se nos relatórios individuais a predominância de relatos superficiais do desenvolvimento da criança. Uma criança de 3 anos pode não conseguir se equilibrar em um muro, batucar e decorar músicas, mas é excelente em combinar cores, peças e conhece vários animais e os sons que 
emitem. Isso nos leva a crer que tais atividades descritas com rendimento insatisfatório no relatório apenas não lhe despertavam interesse, já que estava em um nível muito mais avançado em outras áreas do conhecimento.

Segundo Hoffmann (2012), para superarmos essas práticas que desconsideram as crianças como foco principal da avaliação, é necessário refletirmos com profundidade em duas direções: quanto aos interesses e possibilidades das crianças nas diferentes etapas de desenvolvimento e quanto aos propósitos educativos das práticas docentes.

A autora propõe aos professores que realizem um exercício de reflexão sobre cada criança com a qual convive da seguinte maneira:

1. Observe a criança; 2 . Reflita sobre tudo que sabe sobre ela (idade, características, família, preferências, brincadeiras, perguntas, etc); 3. Recorde fatos do seu cotidiano, como de que forma brinca com determinado brinquedo, como ela questiona sobre uma história contada, como ela se comporta ao chegar a escola, ao se alimentar; 4. Pense em alguma reação curiosa dessa criança; 5. Reflita sobre suas conversas com ela, suas brincadeiras e cuidados necessários (HOFFMANN, 2012, p.63). 
Esse exercício vem como ponto de partida para uma avaliação mediadora efetiva na Educação Infantil. Ao desenvolvê-lo, o professor estará prestando atenção nas crianças, individualmente, exercitando um olhar investigativo e curioso sobre cada uma. Esse "olhar" não é baseado em nenhum roteiro de comportamentos pré-definidos e não tem intenção de comprovar a comunidade escolar o que elas fazem, mas sim descobrir como a criança é de fato, respeitando sua espontaneidade.

Outro instrumento de avaliação utilizado na Educação Infantil é o dossiê. Dossiê, de acordo com o dicionário informal, "é uma coleção de documentos ou um pequeno arquivo que contém papéis relativos a determinado assunto, processo, negócio, fato ou pessoa". O professor ao documentar as atividades realizadas pelas crianças deve se perceber partícipe desse processo, responsável pela história, pelos conhecimentos construídos por ela assim, a amostra das suas produções terão significado pedagógico e serão representativos do acompanhamento do seu desenvolvimento.

Nas instituições, normalmente esses "dossiês" são as tradicionais "pastas de trabalhos" das crianças que costumam ser entregues no final do no letivo em reuniões de pais. Professores escolhem desenhos, pinturas, fotos de atividades sem terem uma 
intencionalidade, seguindo um padrão, ou, muitas vezes, classificando as atividades "mais bonitas" realizadas pelos alunos.

Essa coleta aleatória das produções das crianças não tem significado dentro da avaliação mediadora por não revelarem o processo evolutivo das crianças das suas descobertas, das suas vivências, das linguagens e expressões artísticas, da sua oralidade, das interações com os outros, no desenvolvimento motor, entre muitos outros.

Relatórios e dossiês vão muito além da observação e da representação das produções de trabalho, como se refere Madalena Freire (1989):

A observação é uma ação estudiosa da realidade. Estudo quando tenho uma pauta, quando eu direciono o meu olhar. Quando observo, ordeno, seleciono, diagnostico significados, classifico questões. É uma ação altamente reflexiva. É diferente do que registrar mecanicamente tudo o que se vê ou se está ali olhando (FREIRE, 1989, p.3).

Os relatórios de avaliação, tanto quanto os dossiês, se fundamentam por anotações frequentes do cotidiano da criança, de maneira que venha subsidiar o trabalho junto a ela, revelando o caminho que o professor deve seguir ao planejar melhores estratégias de aprendizagem. Tais registros devem ser considerados sempre como 
provisórios, referentes apenas a um momento da criança, em vez de ter como finalidade apontar resultados alcançados por ela. Um relatório de avaliação/dossiês nesses moldes busca substanciar o processo de desenvolvimento percorrido pela criança em seu permanente anseio de superação, conquistas e descobertas.

Dessa maneira, o professor, ao planejar sua ação pedagógica, deve analisar os componentes curriculares que norteiam o processo avaliativo da educação para que possa articular as áreas do conhecimento que deve permear o cotidiano de sua sala de aula. Mas o que compõe o planejamento na Educação Infantil?

O planejamento na Educação Infantil deve ser composto pelas áreas do desenvolvimento infantil (desenvolvimento motor, conhecimento físico, conhecimento lógico-matemático, conhecimento social e representações, desenvolvimento socioafetivo); pelas áreas do conhecimento (língua portuguesa e literatura, matemática, história, geografia, ciências naturais, música, dança, teatro, desenho, pintura, escultura, religião, educação física, informática e outras ciências); pelas atividades práticas e projetos pedagógicos (ouvir, contar e representar histórias, conversar sobre fatos do cotidiano, brincar de faz de conta, jogar, observar e cuidar das plantas e animais, desenhar, pintar, rasgar, amassar, etc).

(C) Silva; Menezes - DiversaPrática, v. 4, n. 1, p. 43-70 - $1^{\circ}$ semestre 2017 
Todos esses componentes curriculares articulam-se no sentido de constituir referências ao planejamento da ação pedagógica, cuja finalidade primordial é alcançar os objetivos cognitivos e socioafetivos, fundamentados na concepção de criança como sujeito social, interativo, produtor do seu conhecimento a partir de suas vivências no cotidiano dentro da escola e também fora dela.

Outro ponto significativo para embasar a prática pedagógica é a criação de espaços para conversas durante o ano letivo, onde todas as pessoas que convivem com elas possam conversar sobre diferentes aspectos do seu desenvolvimento. Professores, educadores, supervisores, diretores, auxiliares, pais, devem estar disponíveis para refletir sobre os interesses, as necessidades e as conquistas das crianças para que possam respeitá-las e compreendê-las em sua singularidade. E em relação às crianças, por que esses relatórios de avaliação/dossiês são importantes?

Segundo Hoffmann (2012), os relatórios de avaliação e dossiês são importantes para as crianças porque são constituídos da história do seu processo de construção do conhecimento, assegurando a sua individualidade no contexto escolar, garantindo o olhar reflexivo do professor sobre suas conquistas, descobertas, interesses, possibilidades e limites de cada criança. Ele se torna um partícipe significativo de suas 
vivências, contextualizando o seu processo educativo, socializando esse processo para a família e também para os outros profissionais que também trabalharão com ela nos anos seguintes.

Esse conjunto de instrumentos avaliativos na Educação Infantil favorece o acompanhamento individual ao longo de toda a escolarização. O professor do ano seguinte precisa conhecer o que se passou com a criança no ano anterior para dar continuidade nesse processo educativo, por isso as cópias dos relatórios e algumas produções das crianças devem ficar arquivadas na escola para documentar o desenvolvimento das crianças.

\section{CONSIDERAÇÕES FINAIS}

Ao estudar afundo concepções sobre avaliação dentro de uma instituição as discussões apontam para a necessidade de mudanças na estrutura escolar, no formato pedagógico, no lidar com a formação do conhecimento e isso desestabiliza os diretores, coordenadores, professores, funcionários, pais e até mesmo as crianças. Existe o medo de os profissionais assumirem o compromisso da mudança que implicará na desestabilização de práticas adotadas há décadas e já consolidadas e no final não conseguirem atingir resultados satisfatórios.

(C) Silva; Menezes - DiversaPrática, v. 4, n. 1, p. 43-70 - $1^{\circ}$ semestre 2017 
A adoção dessa prática avaliativa não interfere somente na relação professor/criança, mas em todas as relações que acontecem dentro de uma ação educativa. Discutir amplamente as relações de vida, suas crenças e sentimentos dos profissionais são essenciais para a reconstrução de um processo avaliativo mediador na Educação Infantil e isso não é nada fácil.

Avaliar é muito mais que apontar o que a criança sabe ou não, o que consegue ou não, encaixa-la dentro de um roteiro padronizado que pouco tem a ver com o que a criança adquiriu de conhecimento e as descobertas que teve. Dessa forma, o professor tem que estar disposto a mudar e a procurar estratégias para propor intervenções pedagógicas significativas para que seus alunos, de forma individualizada, possam construir o conhecimento e, aos poucos, ir desconstruindo a cultura de que o único culpado pelo fracasso do aluno é ele próprio. Assim, a avaliação tornou-se uma ferida que não deve ser mexida para não atrapalhar o andamento burocrático e pedagógico dentro da escola. Sempre foi assim e sempre deu certo.

No entanto, se levarmos o sentido da palavra avaliação para os nossos atos diários, como avaliação da situação financeira, por exemplo, que significa para cada um de nós refletir sobre a situação atual, para melhorar nossas vidas, ela passa a ter significado palpável e 
estimulador. Todos os dias traçamos metas, trilhamos os caminhos que devemos percorrer e focamos no objetivo que queremos atingir. Planejamos as melhores soluções e amadurecemos os erros e as tentativas frustradas.

Assim, como ocorre à avaliação em nossas vidas, também deve ocorrer à avaliação dentro das escolas. Se a avaliação na vida possui um gosto de recomeçar, organizar para melhorar, por que na escola ela se mantém com significado seletivo, de constatações, de julgamentos, de fracassos, articulada por períodos e datas rígidas.

O professor de Educação Infantil, no seu dia a dia, tem muitas tarefas a cumprir, além tentar conseguir adaptar o seu planejamento à rotina de uma sala de aula com alunos de 2 à 5 anos não é uma tarefa fácil. A prática avaliativa mediadora insere-se nesse cenário como um instrumento de reflexão auxiliando o professor a identificar as mudanças necessárias no processo avaliativo, como também direcionar e permear sua prática, tornando-se um aprendiz que reflete sobre o seu fazer pedagógico e protagonista do seu próprio aperfeiçoamento. Assim, há a necessidade de os profissionais mudarem sua postura diante da avaliação, mas, muito, além disso, há a necessidade de uma mudança em suas posturas na vida. 


\section{REFERÊNCIAS}

BRASIL, Lei de Diretrizes e Bases. Lei no 9.394/96, de 20 de dezembro de 1996.

BRASIL. Ministério da Educação. Secretaria de Educação Básica. Política Nacional de Educação Infantil: pelo direito das crianças de zero a seis anos à educação. Brasília: MEC, SEB, 2006.

BRASIL, Referencial curricular nacional para a educação infantil/Ministério da Educação e do Desporto, Secretaria de Educação Fundamental. - Brasília: MEC/SEF, 1998. Vol. 1.

BRASIL, Referencial curricular nacional para a educação infantil/Ministério da Educação e do Desporto, Secretaria de Educação Fundamental. - Brasília: MEC/SEF, 1998. Vol. 3.

DICIONÁRIO INFORMAL - avaliar. Disponível em:

<http://www.dicionarioinformal.com.br/dossiê/>, acesso em 15/10/15.

DICIONÁRIO INFORMAL - dossiê. Disponível em $<$ http://www.dicionarioinformal.com.br/dossiê/>, acesso em 26/12/15.

FREIRE, M. Primavera Madalena. Porto Alegre: Prefeitura Municipal de Porto Alegre: SME, 1989. 
HOFFMANN, J. Avaliação e Educação Infantil: um olhar sensível e reflexivo sobre a criança. $18^{\mathrm{a}}$ ed. Porto Alegre: Mediação, 2012. MACEDO, L. A perspectiva de Jean Piaget. Ideias n 2. A pré-escola e a criança, hoje, São Paulo/ Secretaria de Educação, 1988, 48-51 